\title{
Inelastic deformation and failure of tungsten carbide under ballistic-loading conditions
}

\author{
PJ Hazell ${ }^{1}$, GJ Appleby-Thomas ${ }^{1}$, K Herlaar ${ }^{2}$ and J Painter ${ }^{1}$ \\ ${ }^{1}$ Cranfield Defence and Security, Cranfield University, DA-CMT, Shrivenham, Swindon, SN6 8LA, UK \\ ${ }^{2}$ TNO Defence, Security and Safety, P.O. Box 45, 2280 AA, Rijswijk, The Netherlands
}

\begin{abstract}
High-speed photography has been used to investigate the dynamic behaviour of similar grades of WC-Co hardmetals during ballistic impacts with velocities in the range of $28-484 \mathrm{~m} / \mathrm{s}$. Key features of the failure of similar grades of WC-Co materials during complimentary impacts have been observed and discussed. In particular, fast moving fragments were observed to emanate from the point of impact and flow radially across the target's surface analogous to the processes of interface defeat. Further, as the velocity of impact was increased a non-linear increase in the indentation depth was observed that corresponded with an apparent onset of transgranular fracture in the WC crystallites. Comparisons with ANSYS AUTODYN ${ }^{\mathrm{TM}}$ simulations were made and good correlation has been established between the measured inelastic deformation and computations using a simple strain-hardening model.
\end{abstract}

Keywords: hardness measurement; composites; failure; fracture; plasticity.

\footnotetext{
E: p.j.hazell@cranfield.ac.uk

T: +44 (0) 1793785731
} 


\subsection{Introduction}

The design of state-of-the-art armour systems requires an accurate description of both damage initiation and development in the projectile core and the armour material. Therefore, it is essential that reliable descriptions and models of the interaction between projectile and target be developed. Armour-piercing (AP) projectiles often possess cemented tungsten carbide cermet/hardmetal cores (often with a $\mathrm{Ni}$ or Co binder) due to their ability to defeat ceramic-faced armours where steel-cored projectiles would normally fail [1,2]. Various small and mediumcalibre rounds which possess WC-Co cermet cores such as the 7.62-mm AP sniper 9 [3] and 14.5-mm AP BS-41 [4] rounds are available and present significant challenges to armour designers due to their high hardness values and high acoustic impedance. Unfortunately, limited information is available concerning the dynamic material properties of the projectiles and their failure mechanisms. In particular there is a paucity of data on this material's impact response that can serve as validation for numerical models.

Much of the data in the literature concerning the dynamic properties of WC-Co has been derived from plate-impact tests. For example, the dynamic response of both 3-4 wt.\% Ni WC-Ni composites extracted from a 14.5mm BS-41 AP round and 5.7 wt.\% Co WC-Co from Kennemetal Inc. was investigated in [4]. More recently, Appleby-Thomas et al. [5] investigated the dynamic behaviour of a Co-based composite and showed that the Hugoniot Elastic Limit, that is the dynamic strength under 1-D loading conditions, was $3.3 \pm 0.2 \mathrm{GPa}$. Further, a tensile spall strength for this material of $4.38 \mathrm{GPa}$ was measured.

Whereas plate-impact experiments primarily provide dynamic material property information, sphere impact tests provide an opportunity to study both ballistic properties and material fragmentation. Sphere impact tests involving WC-Co projectiles have been conducted in the velocity ranges $0.8-2.5 \mathrm{~km} / \mathrm{s}$ and $2.1-4.1 \mathrm{~km} / \mathrm{s}$ in [6] and [4,7] respectively. Martineau et al. [6] focused on crater formation in relatively ductile High Strength Low Alloy (HSLA-100) steel targets. Impact crater dimensions were directly measured by sectioning target plates and were found to be in good agreement with numerical models based on measured HSLA-100 properties and an elastic-perfectly-plastic WC-Co material model. However, as details of the sphere's fragmentation were not reported in this paper, there is little we can glean from the failure kinetics of the sphere. More enlightening was the work of Hertel, Jr. and Grady [7] who 
used flash X-ray equipment to study the fragmentation of WC-Co spheres during impact on both PMMA and glass targets. Fragmentation initially comprised the separation of spall segments from the front and rear of the spherical projectiles, although as the impact velocity increased so did the degree and homogeneity of projectile comminution as shock energy became more uniformly distributed throughout the projectile. Both axial and radial fragment expansion velocities were used to try and quantify energy dissipation. In the case of impact on PMMA, axial expansion was found to be independent of impact velocity. However, the expansion velocity of radial fragments scaled linearly with impact velocity. Extrapolation of the relationship between radial fragment velocity and projectile impact velocity implied that radial expansion commenced for impact velocities above a threshold of ca. $2.4 \mathrm{~km} / \mathrm{s}$.

Spherical indentation techniques are able to produce damage similar to that caused by ballistic impact - e.g., combinations of ring/cone cracking, elastic-plastic behaviour and meridian cracking. A body of work using WC-Co projectiles or indenters for spherical impact or indentation tests exists [4,6-9] but to the authors' knowledge no information on complimentary WC-Co impacts - namely those involving WC-Co projectiles impacting WC-Co targets - exists in the literature. These types of experiments are important for two reasons. Firstly: the impact pressure in the projectile and the target are similar due to the similar elastic and shock impedance properties and secondly, numerical simulations are some-what simplified due to the analysis of a single target and projectile material.

In this work, the impact of WC-Co spheres with a microstructure similar to that of armour-piercing cores against a target with a similar binder system is presented. Experiments were performed in the impact velocity regime $28-484 \mathrm{~m} / \mathrm{s}$. The impact event and subsequent damage evolution were observed using a high-speed video camera system (a Phantom v.7 camera). Furthermore, a model has been developed within ANSYS AUTODYN ${ }^{\mathrm{TM}}$ to elucidate some for the failure modes that occur when a tungsten-carbide projectile strikes a tungstencarbide target. 


\subsection{Experimental}

\subsection{Materials used}

The WC-Co discs were supplied by Kennametal Engineered Products B.V. (grade G13) and possessed a Co content of 8.5 \%. The spheres were supplied by Atlas Ball and Bearing Co. Ltd. and possessed a Co content of $6.5 \%$. Table I outlines the material properties for the two grades of WC-Co and ballistic-test backing material used in these experiments. The elastic properties for the discs were taken from [5] whereas the properties for the polycarbonate were from [10]. The hardness, HV[2.0], of each grade of tungsten carbide was measured using a HWDM-7 micro-hardness testing machine; resultant values are shown in Table I with a standard deviation calculated from 10 measurements.

TABLE I. MATERIAL PROPERTIES

\begin{tabular}{|c|c|c|c|c|c|c|c|}
\hline Material & $\begin{array}{c}\text { Co } \\
(\mathrm{wt} . \%)\end{array}$ & $\begin{array}{c}\rho \\
\left(\mathrm{g} / \mathrm{cm}^{3}\right)\end{array}$ & $\begin{array}{c}c_{s} \\
(\mathrm{~mm} / \mu \mathrm{s})\end{array}$ & $\begin{array}{c}c_{l} \\
(\mathrm{~mm} / \mu \mathrm{s})\end{array}$ & $v$ & $\begin{array}{c}\mathrm{G} \\
(\mathrm{GPa})\end{array}$ & HV [2.0] \\
\hline WC-Co discs & 8.5 & 14.7 & 4.09 & 6.83 & 0.22 & 246.0 & $1463 \pm 107$ \\
\hline WC-Co spheres & 6.5 & 14.9 & - & - & - & - & $1731 \pm 40$ \\
\hline Polycarbonate & - & 1.2 & 0.88 & 2.18 & 0.40 & 0.9 & - \\
\hline
\end{tabular}

Backscatter scanning electron micrographs of the two WC-Co grades are presented in Figures 1(a) to (b). The higher atomic number WC-Co grains appear as a light phase in the micrographs, with the Co matrix as dark inter-granular regions. Both WC-Co grades considered exhibited a typical hardmetal microstructure showing a bi-modal WC crystallite distribution with fractions in the 5-10 $\mu \mathrm{m}$ and $<5 \mu \mathrm{m}$ ranges. Image analysis showed that (on average) the larger WC bimodal grain fraction had a larger grain size in the G13 WC-Co at $6.2 \mu \mathrm{m}$ compared to $<5 \mu \mathrm{m}$ for the WC-Co sphere. 
Figure 1: Cross-sectional backscattered scanning electron micrographs of the WC-Co specimens: (a) G13 target discs and; (b) spherical projectiles.

\subsection{Ballistic technique}

The sphere impact tests involved ballistic impact of $\varnothing 12-\mathrm{mm}$ WC-Co projectiles onto $\varnothing 65 \mathrm{~mm}$ $\times 6.35 \mathrm{~mm}$ thick G13 WC-Co discs mounted on $150 \mathrm{~mm} \times 150 \mathrm{~mm}, 12 \mathrm{~mm}$ thick, polycarbonate backing using ca. $0.25 \mathrm{~mm}$ thick layers of slow cure epoxy, Araldite 2015. This arrangement is shown schematically in Figure 2.

Figure 2: Schematic illustration of the sphere impact experimental arrangement.

Both the moment of impact and post-impact behaviour were interrogated using a Phantom v.7 high-speed video camera operating at 38,000 - 42,000 pictures-per-second with a $2 \mu$ s exposure. In addition, projectile/target fragments were recovered and subsequently analysed to provide further insight into the WC-Co failure mechanisms. The sphere impact tests were carried out using two smooth bore single-stage gas-guns: (1) a $\varnothing 30-\mathrm{mm}, 5-\mathrm{m}$ barrel gun, and; (2) a $\varnothing 22-$ mm, 1.5-m barrel, gun.

\subsection{Modelling technique}

To elucidate the mechanisms of penetration we have conducted a series of computations. All computations were carried out using 2D axial symmetry employing a Lagrangian mesh in the explicit non-linear transient dynamic numerical code - AUTODYN-2D. This software is explained in detail elsewhere [11] and a useful overview of these types of codes is provided by Anderson [12]. However in brief, this code solves the conservations laws of mass and momentum based on initial boundary conditions. The user is prompted for an equation-of-state that describes the pressure in terms of the internal energy and volume and a constitutive relationship that calculates the flow stress in terms of a number of parameters including strain, strain-rate and temperature. Failure models can be introduced to describe the failure.

It should be pointed out that modelling brittle materials such as tungsten carbide is particularly troublesome as there is no experimental data available for the strength of the 
comminuted material. Furthermore, there exists very little data on the dynamic behaviour of tungsten carbide. In particular there is little data on the dynamic fracture characteristics that would lead to an appropriate material model.

Various attempts have been made in the past to model the failure of tungsten carbide materials that have been subjected to dynamic loading. Both Aries et al. [13] and López Puente et al. [14] have adopted the approach of Cortés et al. [15]. In these works, a model originally intended to simulate the failure of ceramics has been used. This involves the use of a pressure dependent yield surface and the evolution of damage that is associated with ceramic fragmentation through a calculated scalar damage parameter. In both cases they were modelling the penetration into a ceramic-faced composite armour using the LAPUA $7.62 \mathrm{~mm}$ armourpiercing bullet.

Holmquist et al. [16] adopted the approach of using both the Johnson-Cook fracture model [17] and a simple principal stress failure model for modelling the penetration of a tungsten carbide -cored projectile through a range of target materials. They concluded that the JohnsonCook fracture model was the best at representing the failure of the core. Their results showed good correlation of a $14.5 \mathrm{~mm}$ BS41 surrogate projectile penetrating monolithic and layered targets - including a ceramic-faced armour. Their material model for the tungsten carbide was based on a material with a 5.7\% Co content that possessed a uniaxial compressive strength of 5.9 GPa. On the other hand, more recently Fountzoulas et al. [18] modelled the penetration of a High-Strength-Low-Alloy (HSLA)-100 steel plate by high velocity WC-Co projectile. They found that, in AUTODYN at least, the Johnson-Cook strength and failure model used by Holmquist et al. in [16] produced disappointing results. Consequently they went on to evaluate two additional models: the Grady spall criterion [19] that was originally developed to predict spall in ductile metals and a simple principal strain failure model with crack softening and stochastic failure. However their work showed that none of the WC-Co failure models were well calibrated for impact velocities over the velocity range of $830-2550 \mathrm{~m} / \mathrm{s}$. As the authors pointed out, the fragmentation behaviour of WC-Co is notably complex on dynamic loading.

Consequently, we have taken a relatively simple approach to simulate the impact behaviour and have adopted the strength model as used by Holmquist et al. given by:

$$
\sigma=A+B \varepsilon_{p}^{n}
$$


where $A$ is the yield strength at zero plastic strain, $B$ is the strain hardening parameter and $n$ is the strain hardening exponent. Our initial values were $A=3.00 \mathrm{GPa}, B=89 \mathrm{MPa}$ and $n$ $=0.65$. From the results of the sphere-impact work we have assumed that the strain-rate hardening effects of the tungsten carbide are negligible in comparison to the strain-hardening effects and consequently they have been ignored.

The polycarbonate data was extracted from the AUTODYN ${ }^{\mathrm{TM}}$ material library [20]. This data was derived from [21]. The strain-rate strengthening behaviour was calculated according to Equation 1 with $C=0.040$ where $C$ represents a strain-rate multiplier as defined in [17]. Failure occurred when the effective plastic strain reached $200 \%$.

The equation of state for polycarbonate and the tungsten carbide was of Mie-Grüneisen form [22] derived from a linear shock-particle Hugoniot thus:

$$
U_{s}=c_{0}+S \cdot u_{p}
$$

where $U_{s}$ and $u_{p}$ are the shock and particle velocities respectively, $c_{0}$ is the bulk sound speed and $S$ is the slope in the $U_{s}$ versus $u_{p}$ Hugoniot. A Grüneisen coefficient $(I)$ is provided to calculate off-Hugoniot shock states [22]. Equation-of-state data is provided in Table II.

Table II: Equation-of-state data for materials used.

\begin{tabular}{|l|c|c|c|}
\hline Material & $c_{0}(\mathrm{~mm} / \mu \mathrm{s})$ & $S$ & $\Gamma$ \\
\hline WC-Co & 5.253 & 1.11 & 1.05 \\
\hline Polycarbonate & 1.933 & 2.65 & 0.61 \\
\hline
\end{tabular}

\subsection{Results and Discussion}

\subsection{Projectile defeat}

Sphere impact tests using the $\varnothing 12$-mm WC-Co projectile were carried out at velocities ranging from $28 \mathrm{~m} / \mathrm{s}$ to $484 \mathrm{~m} / \mathrm{s}$. On contact, material was radially dispersed across the surface of the target. This occurred via two different forms: (a) comminuted projectile material travelling at 
velocities in excess of the impact velocity and; (b) larger fragments (ca. $1 \mathrm{~mm}$ ) moving at a velocity less than the impact velocity.

Figure 3 shows an example of the early stages of impact where the projectile is travelling at $220 \mathrm{~m} / \mathrm{s}$. On contact, fast-moving material is seen to emanate radially from the point of impact, in this case, with a measured velocity of ca. $620 \mathrm{~m} / \mathrm{s}$. Occasionally however, this fast moving material was not visible due to the presence of an incandescent flash as seen in Figure 4, a phenomenon that may well have been due to the small comminuted particles igniting on impact.

Figure 3: Initial stages of impact and projectile failure; impact velocity $=220 \mathrm{~m} / \mathrm{s}$.

Figure 4 shows a typical sequence of high-speed video images from the $195 \mathrm{~m} / \mathrm{s}$ test. A small part of the acetal sabot is also visible in the frame but had no effect on penetration. Before failure of the target disc, the projectile is observed to fracture and spread radially across the target surface. This is similar to the process of interface-defeat that has been observed with projectiles striking ceramic targets and occurs when the projectile is eroded whilst there is no significant penetration into the target [23]. This was observed for all shots with a velocity of less than 484 $\mathrm{m} / \mathrm{s}$.

Figure 4: Phantom high-speed video showing a Ø 12-mm WC-Co sphere impacting a WC-Co disc mounted on polycarbonate backing; impact velocity $=195 \mathrm{~m} / \mathrm{s}$.

The radial velocity of the larger, slower-moving fragments was measured for each of the experiments as they appeared to flow on the front surface of the target. Figure 5 shows the variation of fragment radial velocity with impact velocity. There are several things to note from these measurements. Firstly, impacting the target at $28 \mathrm{~m} / \mathrm{s}$ resulted in no fragmentation of the sphere (and indeed no permanent deformation) and therefore represented the lower limit of this behaviour. Increasing the velocity to $57 \mathrm{~m} / \mathrm{s}$ resulted in chips fracturing off the front of the projectile with the predominate mass of the projectile rebounded from the target. Rebounding of the projectile fragments was observed until an impact velocity of $137 \mathrm{~m} / \mathrm{s}$ where the projectile fragmented and dispersed radially across the target's surface. Secondly, the radial velocity appeared to scale linearly with impact velocity up to $281 \mathrm{~m} / \mathrm{s}$. This is consistent with the conservation of momentum of a projectile impacting and fragmenting against a rigid non- 
deforming plate where all of the projectile's momentum is projected radially. Thirdly and finally, at velocities in excess of $281 \mathrm{~m} / \mathrm{s}$, the radial velocity appeared to become constant. This may have been due to the fact that it was particularly difficult to discern the main fragmented front due to the impact flash. On the other hand, it might suggest that we no longer observed increased radial flow but rather penetration ensued. Indeed, for the target that was struck at $484 \mathrm{~m} / \mathrm{s}$, littleto-no radial movement of projectile fragments was observed. Further, on analysis of the polycarbonate back-plate, a circular indentation was present with a diameter that was similar to the projectile suggesting that the projectile had remained intact long enough to impact the backplate.

Figure 5: Variation of radial fragment velocity with impact velocity.

Following each test the majority of fragments of both the projectile and target were recovered and partially reconstructed. In general, the outer regions of the targets survived while the central impact sections were comminuted to varying degrees. The WC-Co targets failed via a series of radial cracks bisected by concentric cracks presumably arising from hoop stresses. The $195-\mathrm{m} / \mathrm{s}$ test was repeated with the high-speed camera angled at $24^{\circ}$ to the target surface to allow further investigation of this failure mode. A series of frames from the resultant high-speed video are shown in Figure 6. Here, the radial cracks began to form within $47 \mu$ s after impact and continued evolving as dwell occurred. Subsequently when the surface strength of the target was overcome, fracture into numerous radial segments occurred.

Figure 6: Phantom high-speed video showing a Ø 12-mm WC-Co sphere impacting a WC-Co disc mounted on polycarbonate backing; impact velocity $=195 \mathrm{~m} / \mathrm{s}$; observation angle $24^{\circ}$.

\subsection{Fracture morphology}

The morphology of the recovered projectile material was studied to provide further insight into the fracture behavior of WC-Co. Previous work on the fracture of brittle particles/projectiles has largely focused on either: the statistics of fragment distribution via witness-plate and finite element modelling techniques [24,25], or; fragmentation of glass particles, e.g. [26-28]. The mode of fracture has been linked to the velocity of impact. 
Fragment morphology was observed to change with impact velocity and was investigated for impact velocities of $\geq 137 \mathrm{~m} / \mathrm{s}$ which represented the lower-bound of projectile failure and flow across the surface of the target. The degree of comminution of the projectile increased with increasing impact velocity. Consequently, the total proportion of projectile material recovered decreased in a linear fashion from ca. $50 \%$ at $137 \mathrm{~m} / \mathrm{s}$ to ca. $7 \%$ at $484 \mathrm{~m} / \mathrm{s}$. Projectile fragments generally comprised: (1) small, 1-2 mm surface chips; (2) larger, $2 \mathrm{~mm}+$ conical fragments, and; (3) at higher impact velocities a central crushed cone representative of the point of impact. At $137 \mathrm{~m} / \mathrm{s}$ segments ranging in size from 1-8 mm were recovered. All fragments were conical, with the smaller 1-2 mm fragments appearing to represent material detached from the sphere's surface. Similar detached surface fragments formed during the fracture of glass spheres have been attributed to the interaction of Hertzian ring and cone cracks [26]. Counterintuitively the more finely comminuted material was likely to have originated from the rear of the projectile. This was evidenced by the fact that at 195-484 m/s the impact face of the target was recovered in the form of a flattened cone of WC-Co. Up to $281 \mathrm{~m} / \mathrm{s}$ smaller fragments again appeared to represent chips from the surface of the sphere. However at an impact velocity of 339 $\mathrm{m} / \mathrm{s}$ no fragments smaller than $2 \mathrm{~mm}$ were recovered and at $484 \mathrm{~m} / \mathrm{s}$ only the flattened central cone was present. Consequently it was supposed that comminution behind the impact face became so great that all material from this region was lost.

Fragments from the impact zone of the WC-Co disc targets were also recovered, as typified by the crater shown in Figure 7(a). Several of these exhibited either complete or partial elements of plastic deformation at the point of impact. Additionally, in several cases a Hertzian cone from behind the point of impact was recovered either separately or still adhered to the polycarbonate backing.

Figure 7: Examples of recovered central G13 WC-Co target material, impact velocity =195 m/s.

\subsection{Inelastic deformation}

Figure 7(a) shows a typical recovered impact crater (shown with an intact $12 \mathrm{~mm}$ projectile insitu for scale in Figure 7 (b)), complete with crater lip, formed when a WC-Co projectile impacted a target WC-Co disc at $195 \mathrm{~m} / \mathrm{s}$. It is interesting to note the inelastic nature of this impact, as compared to the brittle failure observed in tungsten carbide core-on-core impacts [29]. 
In line with impact on other brittle materials [26, 30], the impact of the WC-Co sphere appears to have led to the formation of surface ring cracks with the subsequent symmetric hoop stresses leading to the formation of a typical Hertzian cone. Recovery or reconstruction of the plastically deformed impact zones proved possible for impact velocities up to $317 \mathrm{~m} / \mathrm{s}$. In the other cases, target comminution proved too great for more than a partial recovery of the impact region. Where the point of impact was retrieved with sufficient features remaining for analysis, we established an 'equivalent DoP'. Firstly, the diameter of the crater was accurately measured. The depth was then estimated geometrically from Pythagoras according to Equation 3 assuming that the penetration cavity was spherical in shape.

$$
d_{p}=r-\sqrt{r^{2}-\left(\frac{w}{2}\right)^{2}}
$$

where, $d_{P}$ is the depth of penetration, $r$ is the radius of the indenting sphere and $w$ the measured diameter of the indentation. To compare with this data, where possible the maximum depth of the impression was measured using a dial-test-indicator accurate to $2 \mu \mathrm{m}$ per division for shallow indentations and $10 \mu \mathrm{m}$ per division for the deeper indentations. This data is plotted against impact velocity in Figure 8.

At low impact velocities (са. $57 \mathrm{~m} / \mathrm{s}$ ), the difference between the calculated depth (assuming a spherical indentation) and the measured depth was relatively small, however the difference appeared to grow as the impact velocity was increased. This was mostly due to the elastic-plastic deformation in the projectile and the target. However, for the $28 \mathrm{~m} / \mathrm{s}$ impact-case no permanent deformation was measured in the recovered tungsten carbide sphere whereas an indentation of diameter of $2.61 \mathrm{~mm}$ and depth of $0.034 \mathrm{~mm}$ was measured in the target; the calculated equivalent DoP was $0.14 \mathrm{~mm}$. As the calculated DoP assumed a spherical impression, the difference observed between the measured and calculated values is attributed to the elasticity of the sphere and target.

Up to an impact velocity of $137 \mathrm{~m} / \mathrm{s}$, failure of the projectile was noted to occur on rebound. At ca. 195 m/s, there was a noticeably sharp increase in the depth-of-penetration. We attribute this to an abrupt increase in the level of cracking below the contact surface. Indeed, examination of scanning electron micrographs of the fracture surfaces around the impact crater 
revealed extensive inter-granular and trans-granular cracking at impact velocities of $220 \mathrm{~m} / \mathrm{s}$ and greater (see Figure 9). No such level of cracking was noticeable at impact velocities of less than this.

Figure 8: Variation of indentation depth with impact velocity.

Figure 9: Scanning electron micrograph showing cracking in material situated just below the impact crater; impact velocity $=220 \mathrm{~m} / \mathrm{s}$.

The simulation results using the Holmquist et al. [16] strength model are shown in Figures 10 and 11 . There are several things to note from these results. Firstly, we found that the results are consistent with the experimental data when the work hardening constant, $B$, is reduced from 89 MPa to $45 \mathrm{MPa}$ for both the projectile and the target. As shown, comparison was also made to the case where the projectile's work hardening constant was $89 \mathrm{MPa}$ and the target's $45 \mathrm{MPa}$ consistent with the slightly harder projectile employed (see Table I). Small differences are apparent in the results - in particular the penetration becomes narrower and deeper for the harder projectile. It is also noticeable that at lower impact velocities, the penetration depth appears to mirror the experimental results until a departure at ca. $200 \mathrm{~m} / \mathrm{s}$. This confirms that initially at least, the penetration depth in these early stages is mostly due to the inelastic deformation of the projectile and the target rather than being affected by the fracturing of the projectile. Furthermore, as failure has been suppressed in this model, this lends weight to the fact that extensive failure is occurring in the target leading to deeper penetration at impact velocities of ca. $200 \mathrm{~m} / \mathrm{s}$.

Figure 10: Experimental and numerical evaluation of the diameter of the indentation.

Figure 11: Experimental and numerical evaluation of the indentation depth.

\subsection{Dynamic hardness assessment}


For the low velocity impacts where the sphere remains mostly elastic, it is possible to estimate the dynamic hardness of the target due to the size of the indentation. Previous work has focused on firing tungsten-carbide spheres at metals [3,31]. The calculation of dynamic hardness can be made by a simple energy balance where the kinetic energy of the projectile is consumed by the inelastic deformation of the target material. A simplified approach was adopted by Sundararajan and Tirupataiah [31] where it was assumed that the dynamic hardness of the material could be calculated from

$$
H_{d}=\frac{0.5 m v^{2}}{U}
$$

Where $m$ is the mass of the projectile, $v$ is its velocity and $U$ is the unrelaxed indentation volume. $U$ can be computed easily on the basis of the indentation diameter $(w)$ since the unrelaxed indentation essentially follows the profile of the sphere used in the experiments. There are a number of simplifying assumptions that we have made with this approach, namely: (a) the spherical indenter remains elastic at all times during the indentation process; (b) energy loss through stress waves is negligible compared to the incident energy; (c) the target remains rigid during the indentation period and; (d) work-hardening effects are small.

It should be pointed out that for impact velocities of $57 \mathrm{~m} / \mathrm{s}$ and $83 \mathrm{~m} / \mathrm{s}$ fracture was observed in the projectile post impact therefore for these tests it is likely that assumption (a) mentioned above is not valid. Nevertheless, given the brittle nature of the projectile, we have included these results in our analysis. Based on this approach the calculated hardness values for the experiments where rebound of the projectile was visible are shown in Table III.

Table III: Hardness measurements in the tungsten carbide discs.

\begin{tabular}{|c|c|}
\hline Impact velocity $(\mathrm{m} / \mathrm{s})$ & $H V^{*} / H_{d}(\mathrm{GPa})$ \\
\hline 0 & $14.35^{*}$ \\
\hline 28 & 13.38 \\
\hline 57 & 14.96 \\
\hline 83 & 14.47 \\
\hline
\end{tabular}


Although we must be cautious when analyzing these results due to the simplifying assumptions that have been made, they do suggest that at the low velocity at least this type of material is not sensitive to strain-rate-hardening as has been hinted at by other authors [32]. Further validation of these results is that a simple strain-hardening model is sufficient to predict the diameters of the indentation though a range of impact velocities and strain rates (see Figure $10)$.

Finally, Figure 12 shows a computational result of a tungsten carbide target that has been impacted at $83 \mathrm{~m} / \mathrm{s}$. An image at $1 \mu$ s and $5 \mu$ s after impact has been captured. From this computation it is possible to establish an estimate of the strain-rate during the indentation process. For the highest impact velocity cited in Table III, this simulation shows that reasonably large strain-rates are achieved in the early stages of indentation $\left(10^{3}-10^{4} / \mathrm{s}\right)$. Consequently this reinforces the notion that under ballistic impact conditions (where such strain-rates are commonly achieved), the tungsten carbide material remains relatively insensitive to strain rate. This, at least, raises the prospect of simplifying numerical models when simulating the behavior of armour-piercing cores penetrating targets.

Figure 12: ANSYS ${ }^{\mathrm{TM}}$ AUTODYN simulation result showing the impact of a tungsten carbide disc at $83 \mathrm{~m} / \mathrm{s}$; effective-plastic-strain rate at (a) $1 \mu$ and (b) $5 \mu \mathrm{s}$.

\section{Conclusions}

While the tendency for both projectile and target to fracture during complimentary WC-Co impacts hides some detail with regards to the impacts, a number of conclusions may be drawn from this work:

1) WC-Co discs of thickness $6.35 \mathrm{~mm}$ bonded to a $12 \mathrm{~mm}$ thick polycarbonate backing are able to defeat similar grade $\varnothing 12-\mathrm{mm}$ projectiles at impact velocities up to ca. $280 \mathrm{~m} / \mathrm{s}$ (e.g. surface dwell occurred before projectile penetration).

2) Dwell velocity for spherical impact appears to scale nominally linearly with impact velocity until a critical velocity is reached beyond which the target WC-Co fails.

3) WC-Co fails via a combination of radial and concentric cracking under spherical loading, forming fragments whose size increases both with distance from the point of impact and with 
reduced impact velocity. Additionally, Hertzian fracture mechanics appears to apply to complimentary WC-Co impacts.

4) Numerical modelling techniques have successfully represented the indentation size and predicted the extent of the inelastic deformation.

5) By an assessment of the dynamic hardness of the tungsten carbide we have shown that this material is not strain-rate sensitive and therefore the simulation of tungsten-carbide based armour piercing projectiles is somewhat simplified.

\section{Acknowledgements}

This research has been partly funded by the Dutch Ministry of Defence, through the Research Program "V518 - Munitions and Weapons Effects". Furthermore, the authors would like to acknowledge the invaluable aid of Gary Cooper and Andy Roberts of Cranfield University for conducting the experiments.

\section{References}

1. P.J. Hazell, S. E. Donoghue, C. J. Roberson and P. L. Gotts. 2006. "The penetration of armour piercing projectiles through reaction bonded ceramics," in Advances in Ceramic Armor. Ceramic Engineering and Science Proceedings, 26(7). J. J. Swab, D. Zhu, W. and M. Kriven, eds. pp. 143-150.

2. C. J. Roberson, P. J. Hazell, P. L. Gotts, I. M. Pickup and Morrell R. 2006. "The effective hardness of hot pressed boron carbide with increasing shock stress," in Advances in Ceramic Armor. Ceramic Engineering and Science Proceedings, 26(7). J. J. Swab, D. Zhu, W. and M. Kriven, eds. pp. 151-159.

3. P. J. Hazell, C. J. Roberson, M. Moutinho. Mat. and Des., 29 (2008) 1497-1503.

4. D. Grady, Int. J. of Impact Engng., 23 (1999) 307-317.

5. G. J. Appleby-Thomas, P. J. Hazell, C. Stennett, G. Cooper, K. Helaar, A. M. Diederen, J. Appl. Phys. 105 (2009) 064916.

6. R. L. Martineau, M. B. Prime and T. Duffey, Int. J. of Impact Engng., 30 (2004) 505-520. 
7. E. S. Hertel, Jr., D. E. Grady, “Tungsten Carbide Fragmentation: Experimental Characterization and Numerical Modelling,” Proc. $15^{\text {th }}$ Int. Symp. on Ballistics, Jerusalem, Israel, 21-24 May (1995).

8. A. Wang, J. De Souza, H. J. Rack, Wear, 151 (1991) 157-173.

9. B. R. Lawn, J. Am. Ceram. Soc., 81 (1998) 1977-1994.

10. S. P. Marsh, LASL Shock Hugoniot Data. University of California Press, Ltd., pp.432 (1980).

11. N. Robertson, C. Hayhurst, G Fairlie, Nuclear Engineering and Design 150 (1994) 235241.

12. C. E. Anderson, Jr. Int J of Impact Engng 5 (1987) 33-59.

13. A. Arias, R. Zaera, J López-Puente, C. Navarro. Composite Structures 61 (2003) 151159.

14. J. López-Puente, A. Arias, R. Zaera, C. Navarro, Int J of Impact Engng 32 (2005) 32136.

15. R. Cortés, C. Navarro, M. A. Martínez, J. Rodríguez, V. Sánchez-Gálvez. Int J Impact Eng 12 (1992) 639-651.

16. T. J. Holmquist, G. R. Johnson, W. A. Gooch, Modeling the $14.5 \mathrm{~mm}$ BS41 projectile for ballistic impact conditions. WIT Transactions on Modelling and Simulation 2005;40:6175.

17. G. R. Johnson, W. H. Cook, Eng Fract Mech 21 (1985) 31-48.

18. C. G. Fountzoulas, G. A. Gazonas, B. A. Journal of Mechanics of Materials and Structures 2 (2007) 1965-1979.

19. D. E. Grady, J. Mech. Phys. Solids 36 (1988) 353-384.

20. AUTODYN ${ }^{\mathrm{TM}}$, Century Dynamics Limited, Suite 1, 3 Horsham Gates, North Street, Horsham, West Sussex, UK, RH13 5PJ.

21. S. M. Walley, J. E. Field, Strain rate sensitivity of polymers in compression from low to high rates, DYMAT 1994;J 1:211-27.

22. M. A. Meyer, Dynamic behaviour of materials. New York: John Wiley \& Sons; 1994.

23. C. E. Anderson Jr., and J. D. Walker, Int. J. of Impact Engng., 31 (2005) 1119-1132.

24. V. V. Sil’vestrov, Int. J. of Impact Engng. 29 (2003) 659-670. 
25. V. S. Hernandez, L. E. Murr, I. A. Anchondo, Int. J. of Impact Engng., 32 (2006) 19811999.

26. A. D. Salman, D.A. Gorham, Powder Tech., 107 (1999) 179-185.

27. D. A. Gorham, A.D. Salman. Wear, 258 (2005) 580-587.

28. E. W. Andrews, K. -S. Kim. 1999. “Threshold Conditions for Dynamic Fragmentation of Glass Particles,” Mechanics of Materials 31 (1999) 689-703.

29. K. Herlaar, A. M. Diederen, G. Appleby-Thomas, P. J. Hazell, Ballistic impact experiments of tungsten carbide projectiles onto tungsten carbide targets. In Bless S, Walker JD, editors, Proceedings of the 24th International Symposium on Ballistics, pp. 744-751, New Orleans, USA, 22-26 September (2008).

30. V. S. Hernandez, L. E. Murr, I. A. Anchondo, Int. J. of Impact Engng., 32 (2006) 19811999.

31. G. Sundararajan, Y. Tirupataiah, Acta Materialia 54 (2006) 565-575.

32. E. K. Friis, $\varnothing$ Frøyland, J. F. Moxnes. Experimental and numerical study of the penetration of tungsten carbide into steel targets during high rates of strains. In the Proceedings of the $22^{\text {nd }}$ International Symposium on Ballistics, Vancouver, BC, Canada, 14-18 November 2005, pp. 1130-1137. 


\section{LIST OF FIGURE CAPTIONS}

Figure 1: Cross-sectional backscattered scanning electron micrographs of the WC-Co specimens: (a) G13 target discs and; (b) spherical projectiles.

Figure 2: Schematic illustration of the sphere impact experimental arrangement.

Figure 3: Initial stages of impact and projectile failure; impact velocity $=220 \mathrm{~m} / \mathrm{s}$.

Figure 4: Phantom high-speed video showing a Ø 12-mm WC-Co sphere impacting a WC-Co disc mounted on polycarbonate backing; impact velocity $=195 \mathrm{~m} / \mathrm{s}$.

Figure 5: Variation of radial fragment velocity with impact velocity.

Figure 6: Phantom high-speed video showing a Ø 12-mm WC-Co sphere impacting a WC-Co disc mounted on polycarbonate backing; impact velocity $=195 \mathrm{~m} / \mathrm{s}$; observation angle $24^{\circ}$.

Figure 7: Examples of recovered central G13 WC-Co target material, impact velocity =195 m/s.

Figure 8: Variation of indentation depth with impact velocity.

Figure 9: Scanning electron micrograph showing cracking in material situated just below the impact crater; impact velocity $=220 \mathrm{~m} / \mathrm{s}$.

Figure 10: Experimental and numerical evaluation of the diameter of the indentation.

Figure 11: Experimental and numerical evaluation of the indentation depth.

Figure 12: ANSYS ${ }^{\mathrm{TM}}$ AUTODYN simulation result showing the impact of a tungsten carbide disc at $83 \mathrm{~m} / \mathrm{s}$; effective-plastic-strain rate at (a) $1 \mu \mathrm{s}$ and (b) $5 \mu \mathrm{s}$. 


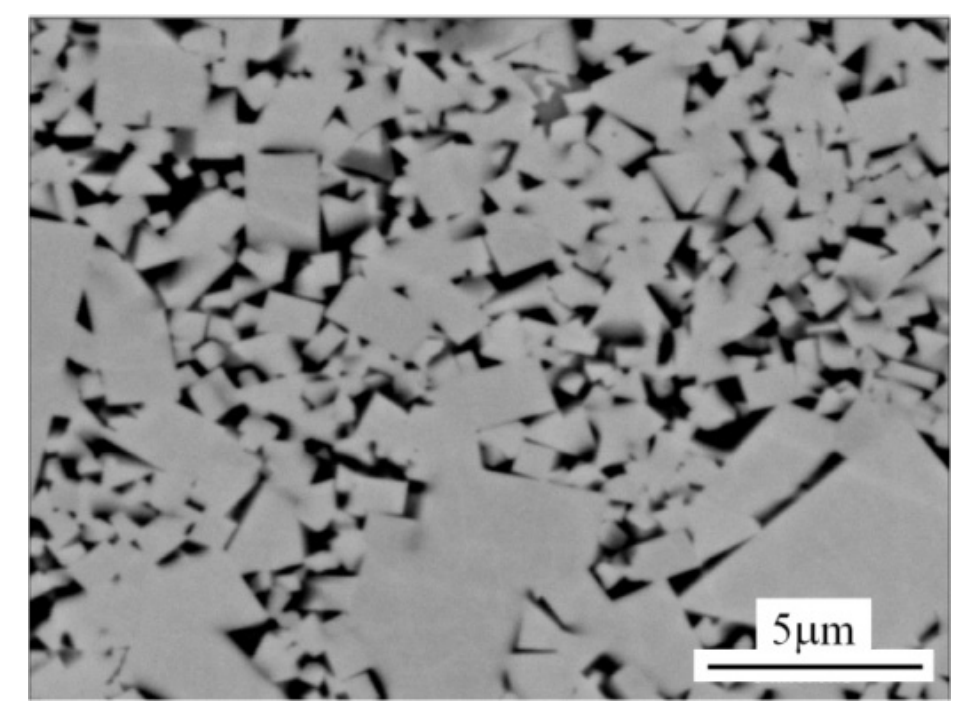

(a)

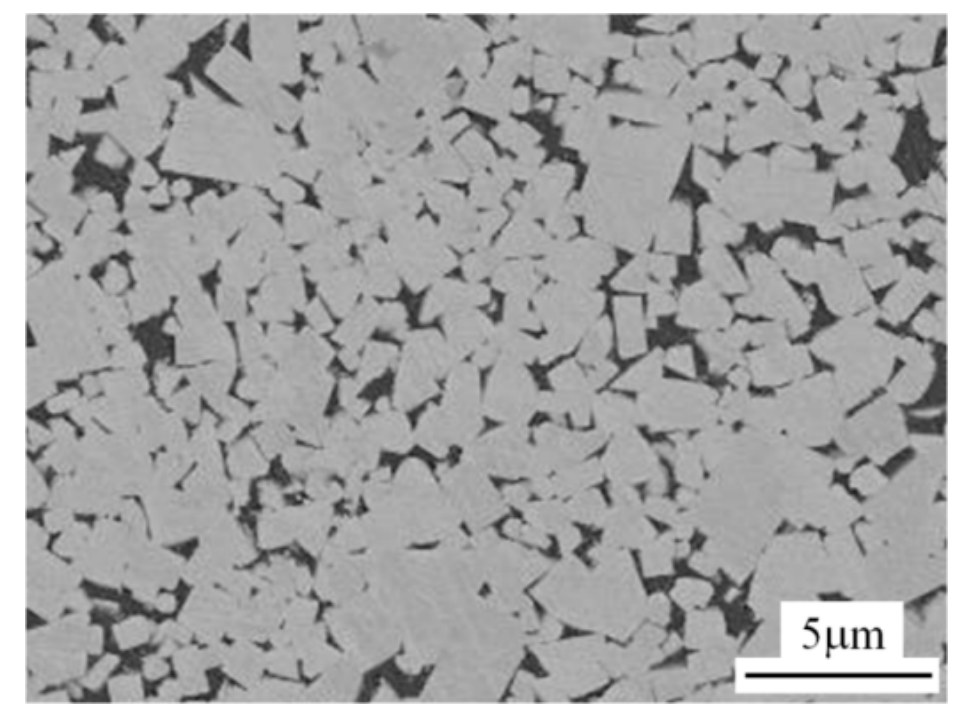

(b)

Figure 1: Cross-sectional backscattered scanning electron micrographs of the WCCo specimens: (a) G13 target discs and; (b) spherical projectiles. 


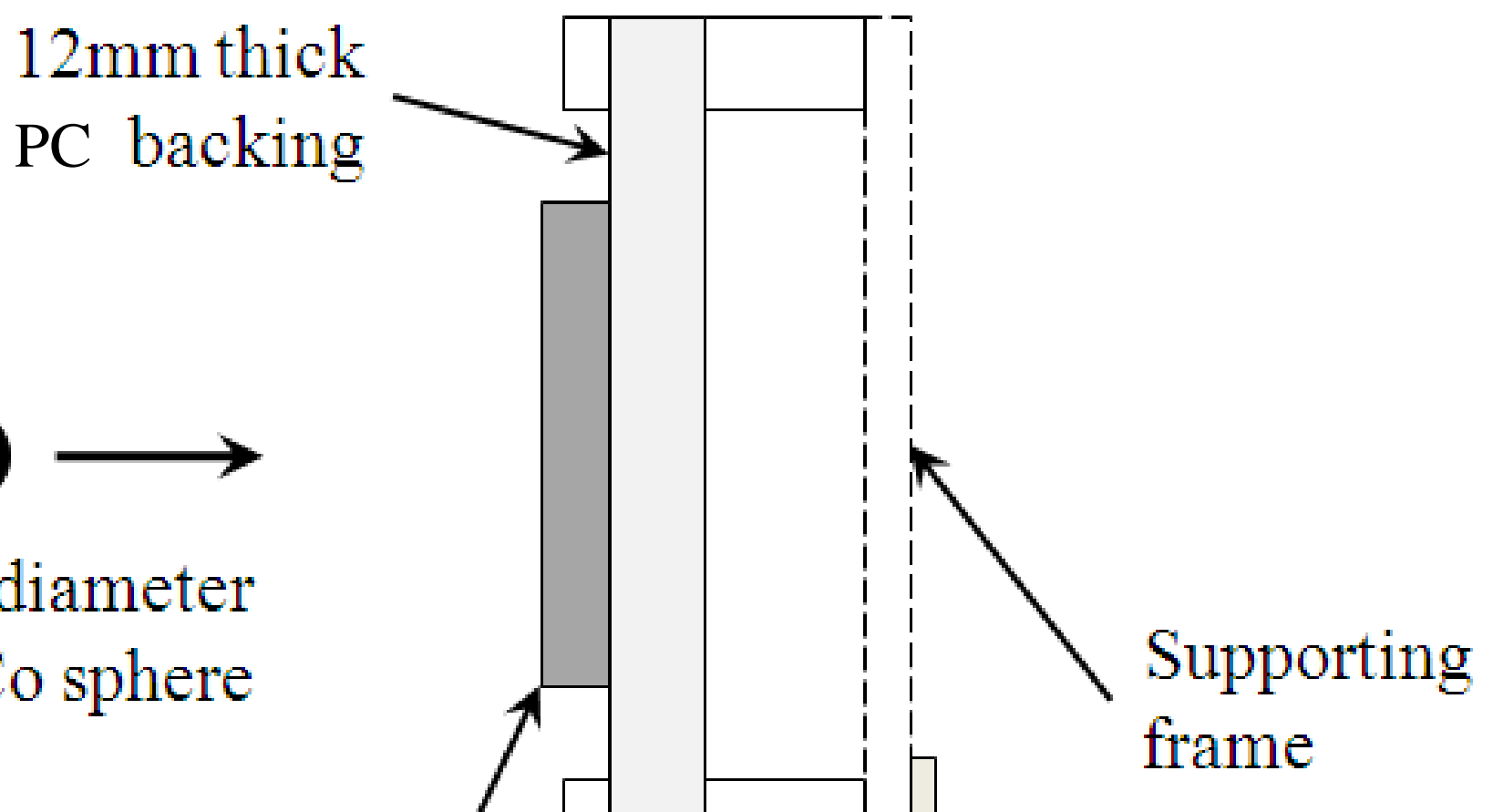

$12 \mathrm{~mm}$ diameter WC-Co sphere

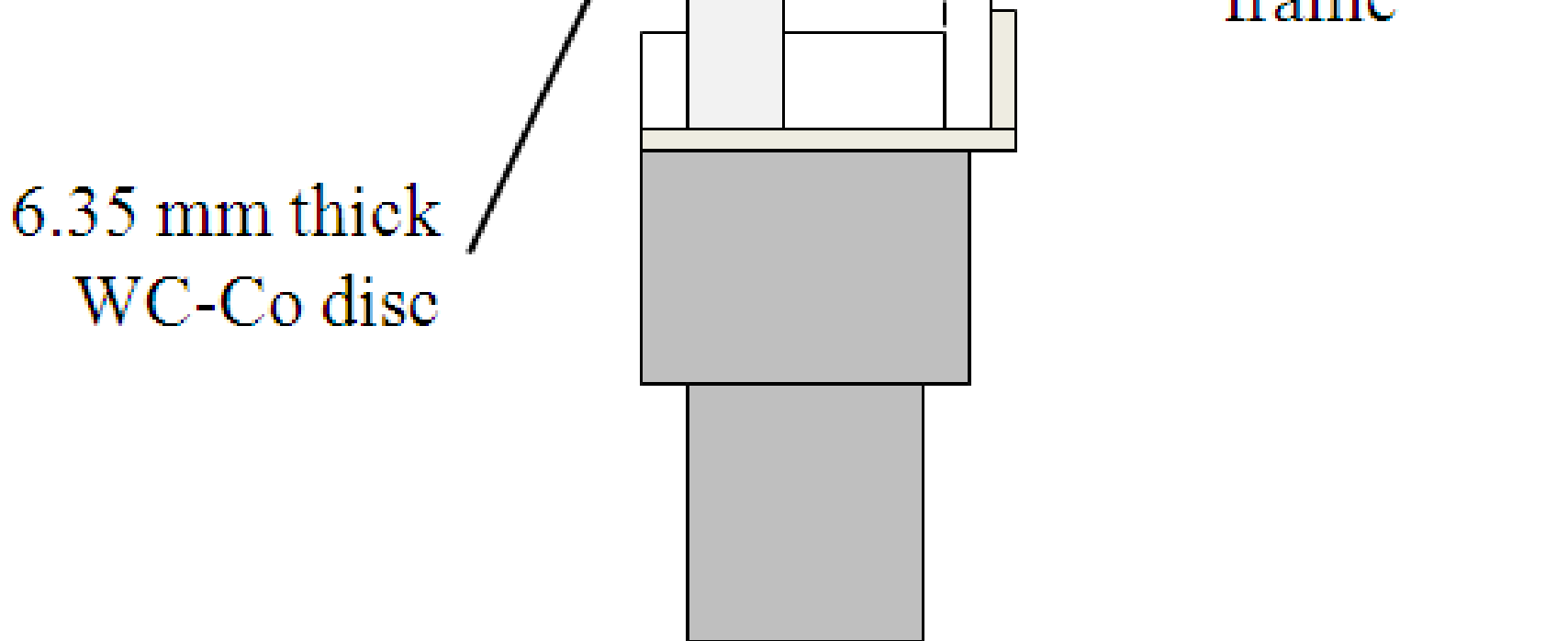

Figure 2: Schematic illustration of the sphere impact experimental arrangement. 


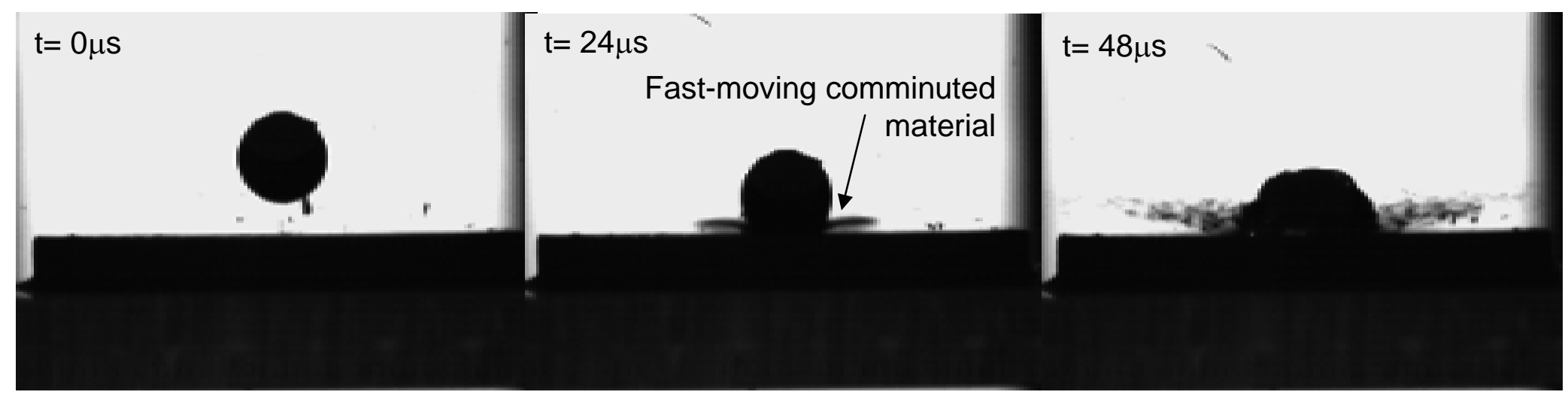

Figure 3: Initial stages of impact and projectile failure; impact velocity $=220 \mathrm{~m} / \mathrm{s}$. 

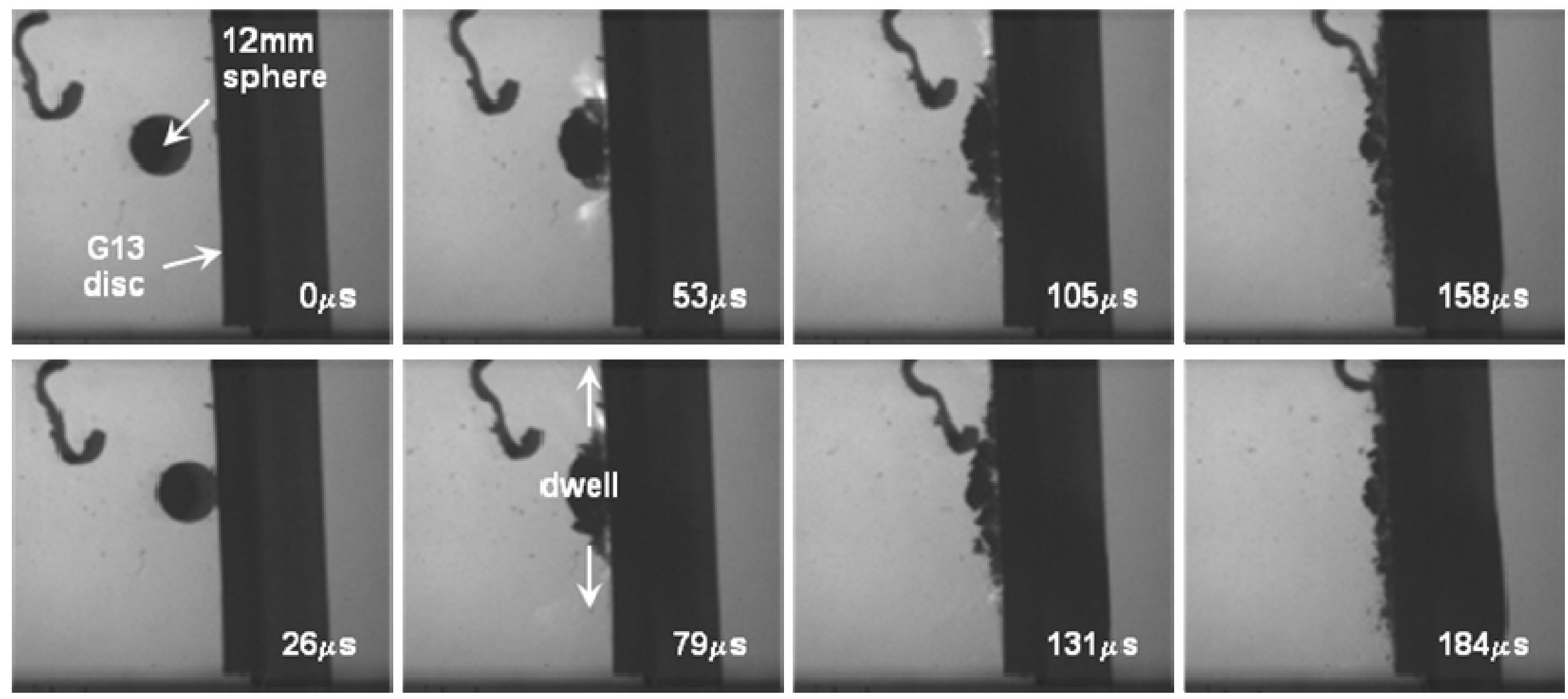

Figure 4: Phantom high-speed video showing a $\varnothing ~ 12-\mathrm{mm}$ WC-Co sphere impacting a WC-Co disc mounted on polycarbonate backing; impact velocity $=195 \mathrm{~m} / \mathrm{s}$. 


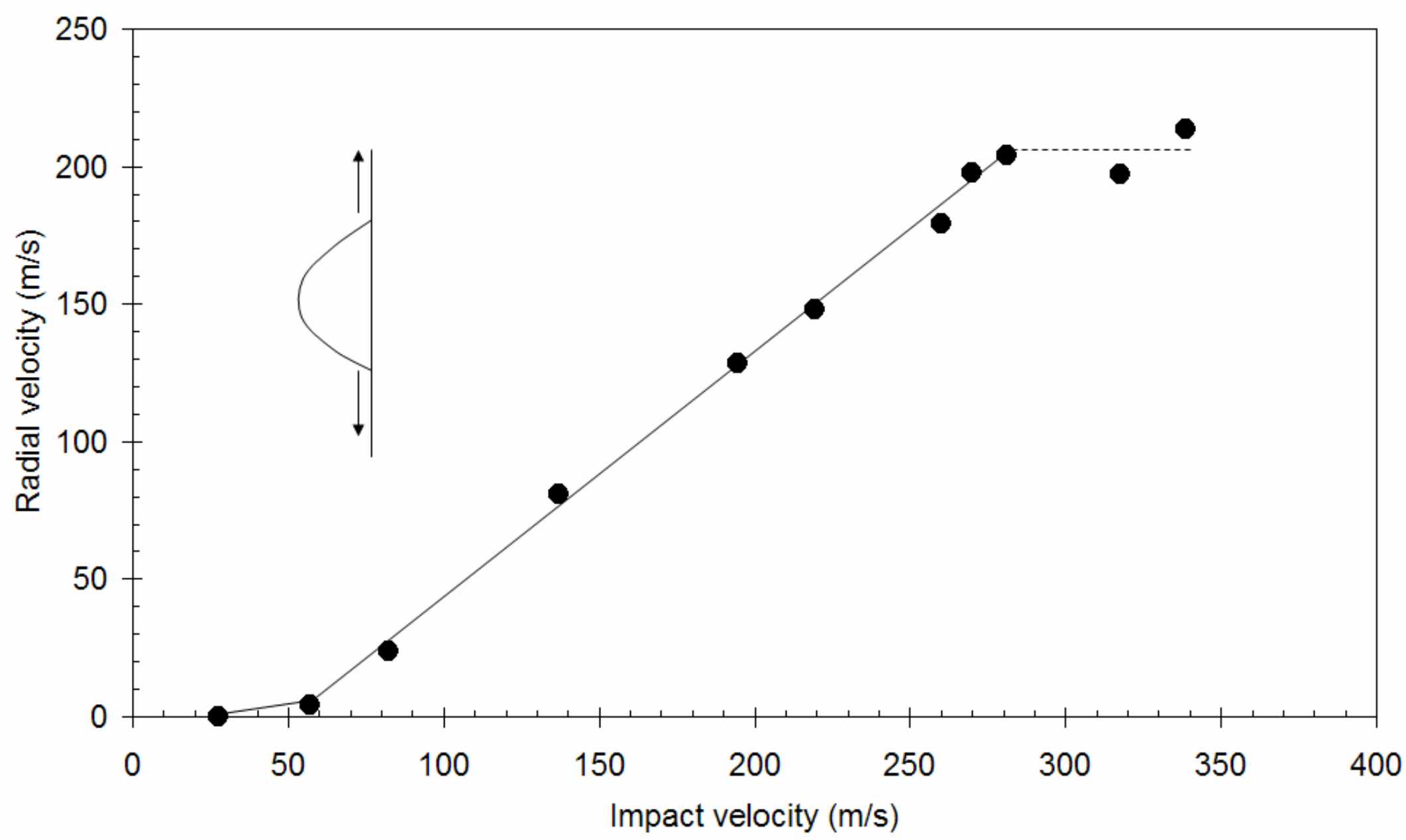

Figure 5: Variation of radial fragment velocity with impact velocity. 


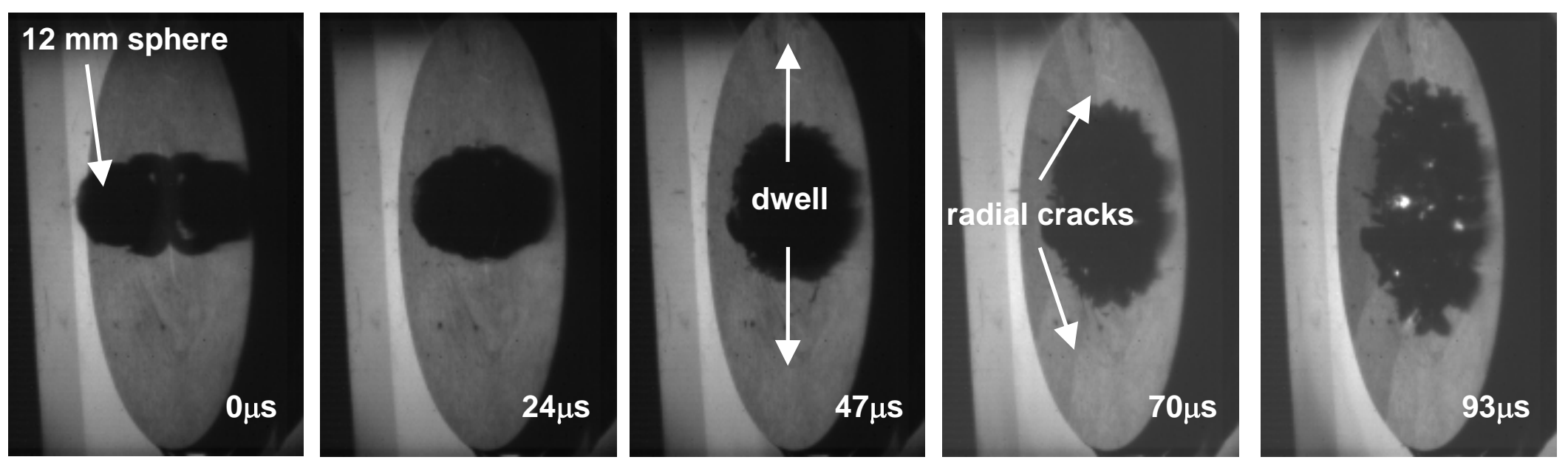

Figure 6: Phantom high-speed video showing a $\varnothing$ 12-mm WC-Co sphere impacting a WC-Co disc mounted on polycarbonate backing; impact velocity $=195 \mathrm{~m} / \mathrm{s}$; observation angle $24^{\circ}$. 


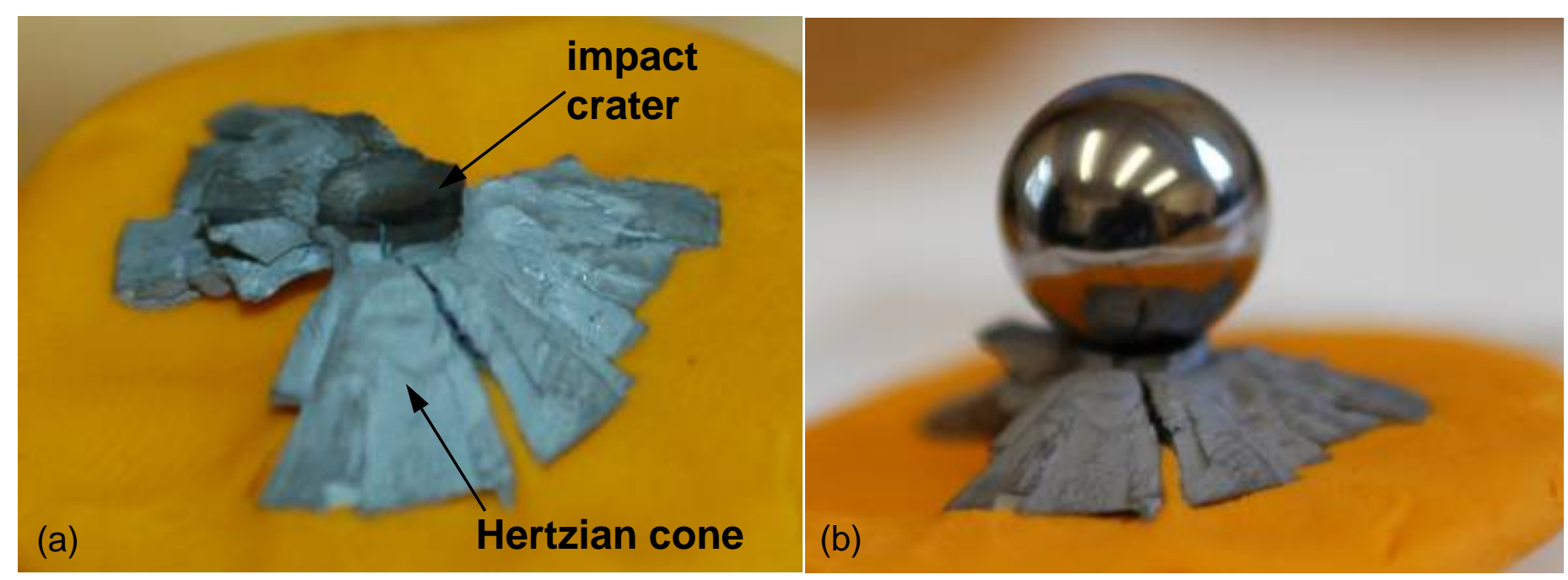

Figure 7: Examples of recovered central G13 WC-Co target material, impact velocity $=195 \mathrm{~m} / \mathrm{s}$. 


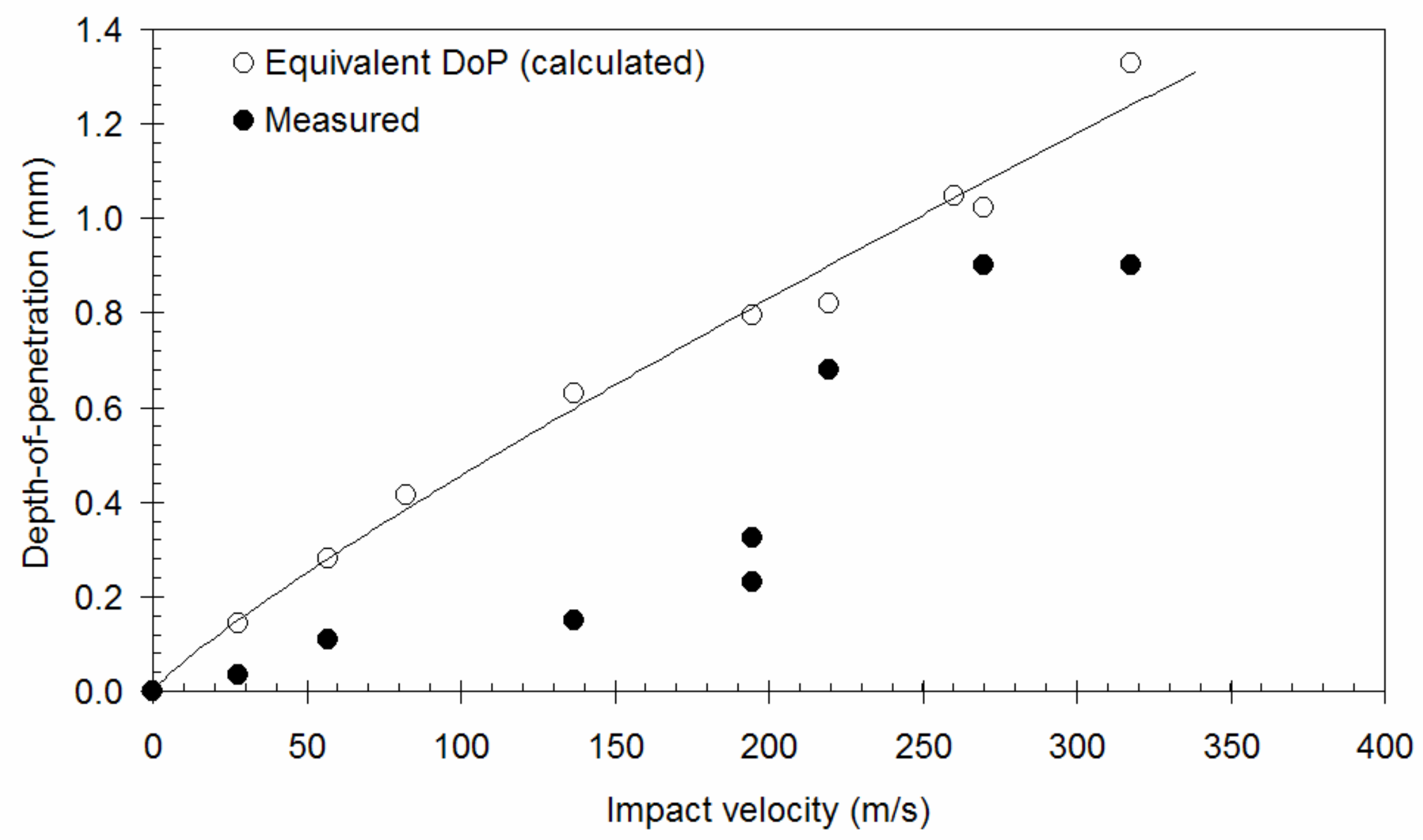

Figure 8: Variation of indentation depth with impact velocity. 


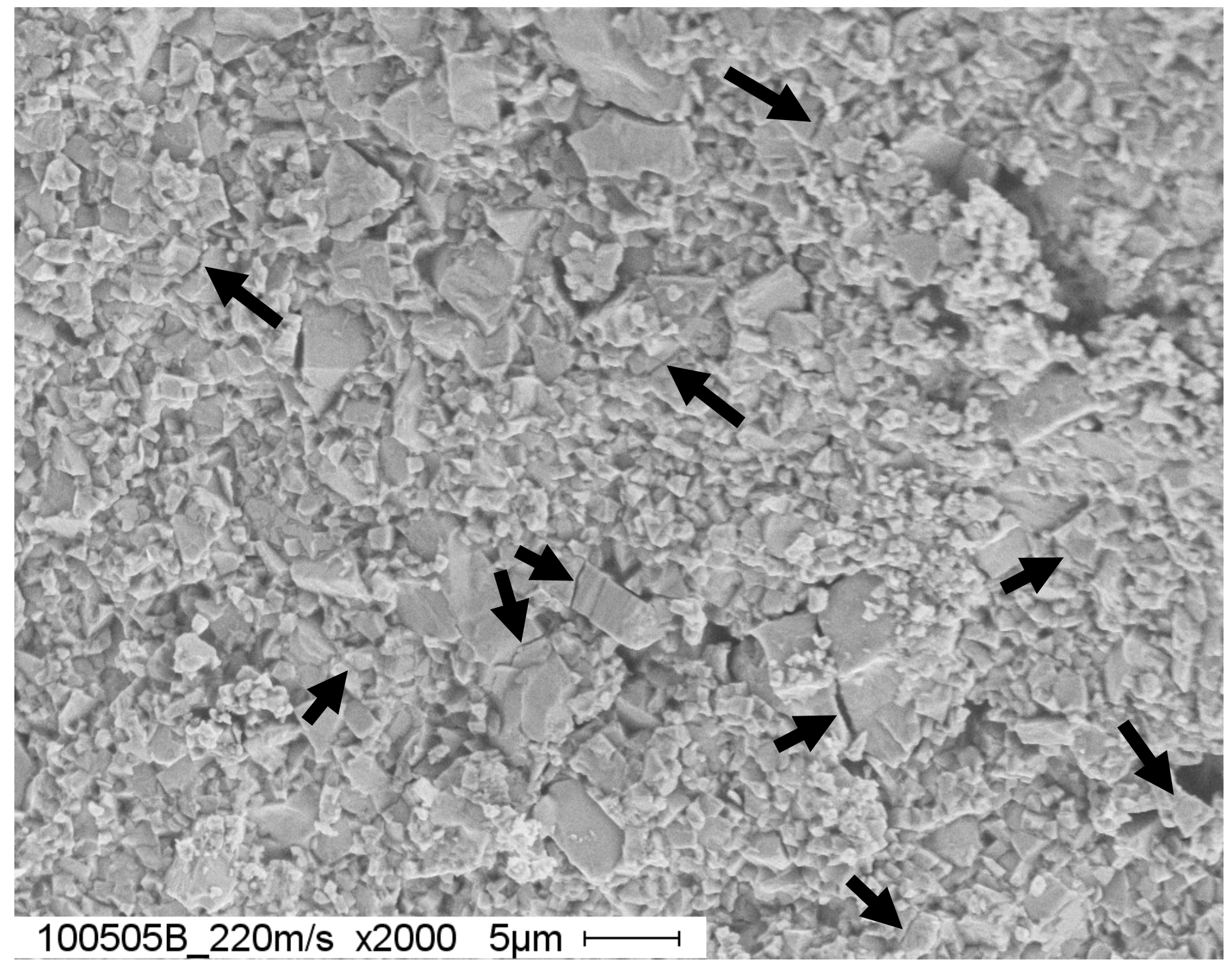

Figure 9: Scanning electron micrograph showing cracking in material situated just below the impact crater; impact velocity $=220 \mathrm{~m} / \mathrm{s}$. 


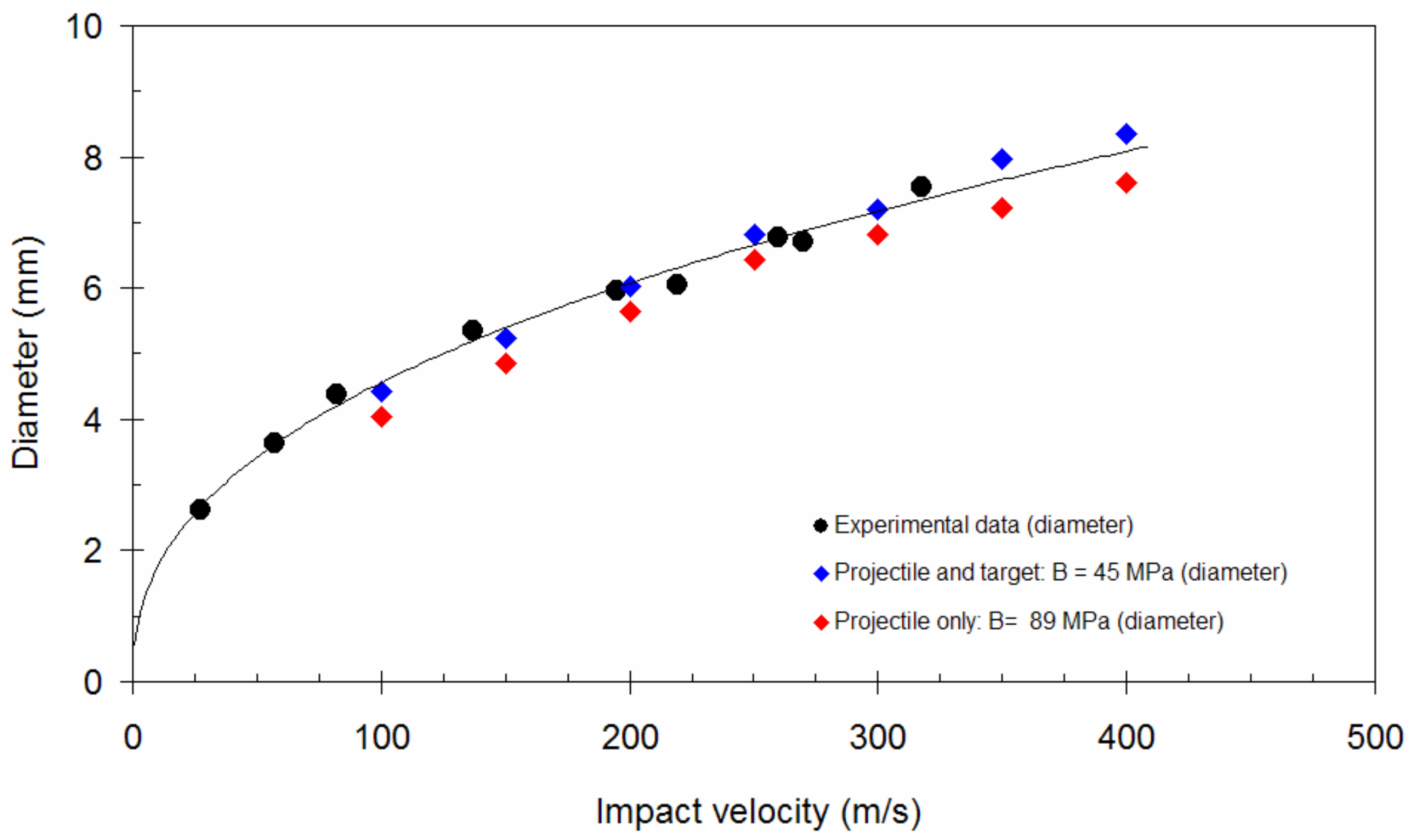

Figure 10: Experimental and numerical evaluation of the diameter of the indentation. 


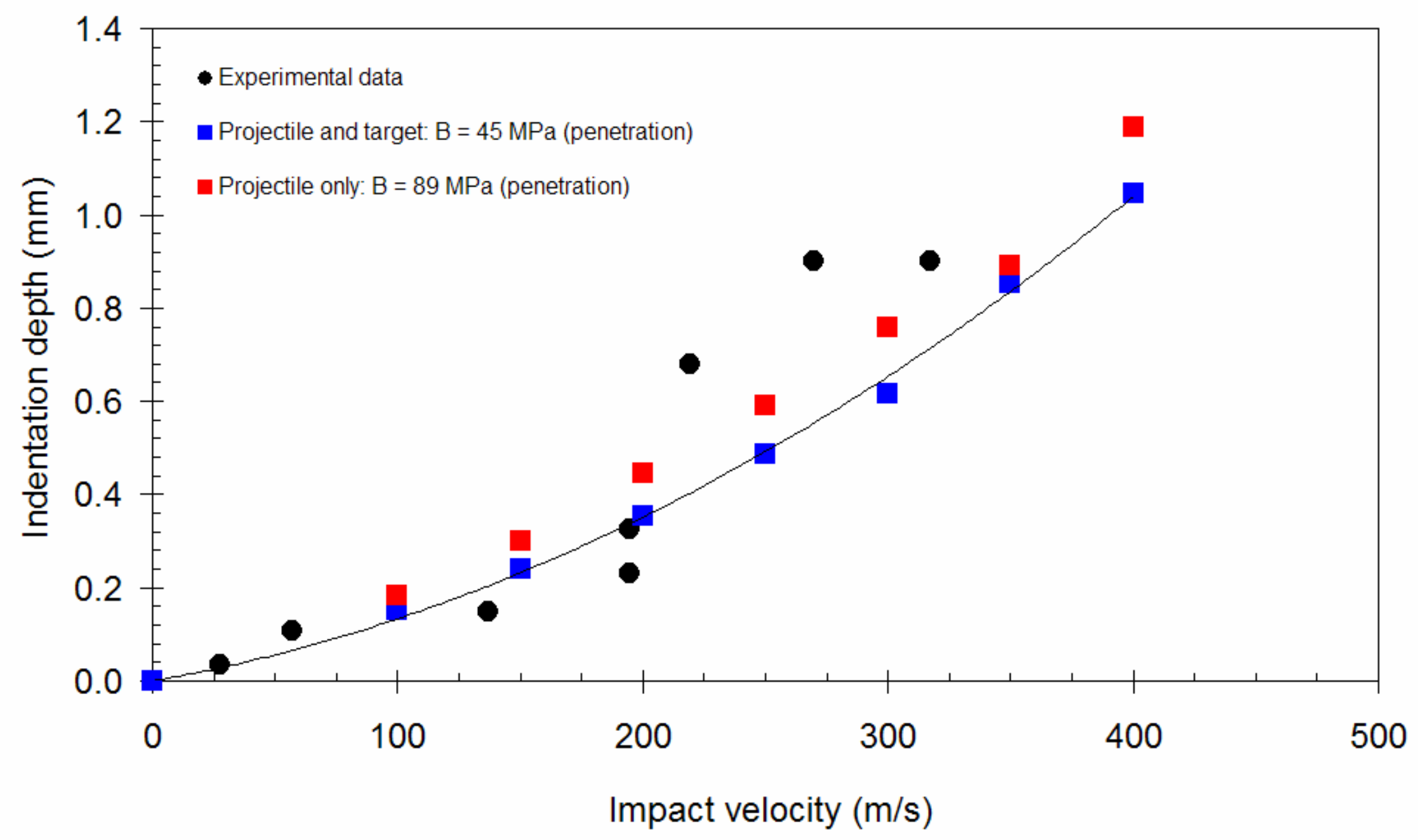

Figure 11: Experimental and numerical evaluation of the indentation depth. 


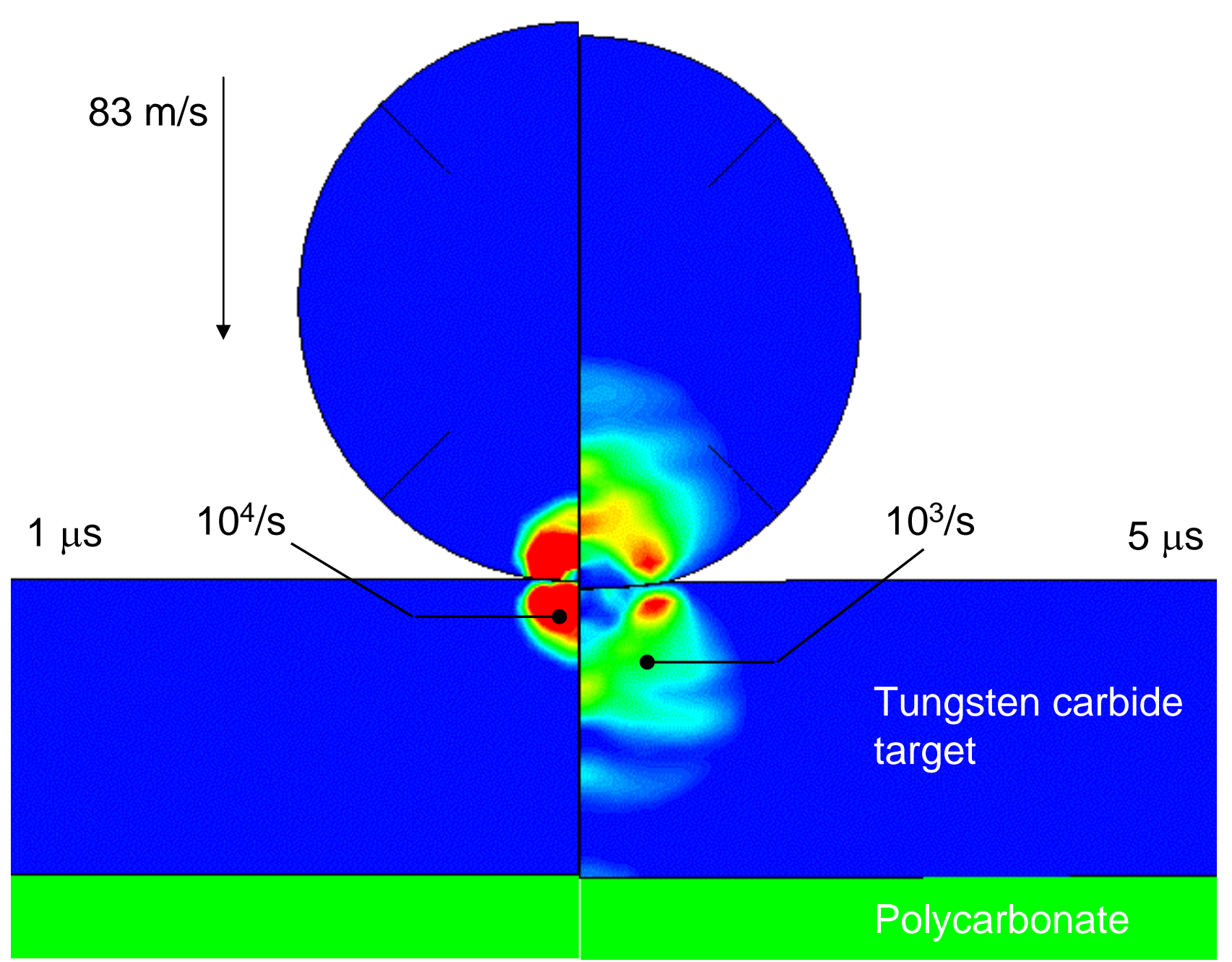

Figure 12: ANSYS ${ }^{\mathrm{TM}}$ AUTODYN simulation result showing the impact of a tungsten carbide disc at $83 \mathrm{~m} / \mathrm{s}$; effective-plastic-strain rate at (a) $1 \mu \mathrm{s}$ and (b) $5 \mu \mathrm{s}$. 